\title{
Frequência de irrigação e adubação nitrogenada na produção de rabanete no nordeste de Mato Grosso
}

Fernando Antônio da Silva Lopes ${ }^{1}$, César Antônio da Silva ${ }^{2}$, Sebastião Geraldo Lopes ${ }^{1}$, Messias Morais Ferreira ${ }^{1}$, Luís Léssi dos Reis ${ }^{3}$

${ }^{1}$ Instituto Federal de Mato Grosso - IFMT, Campus Confresa, MT. ${ }^{2}$ Instituto Federal Goiano - IF Goiano, GO. ${ }^{3}$ Instituto Federal do Sul de Minas Gerais - IFSul de Minas, MG. E-mail: cesar.ufu@gmail.com

\section{Resumo}

O nordeste de Mato Grosso caracteriza-se por apresentar evapotranspiração de referência acima de 4,0 $\mathrm{mm}$ dia $^{-1}$. Essa alta demanda hídrica indica que a frequência da irrigação e quantidade de $\mathrm{N}$ fornecida à cultura do rabanete podem influenciar na economia de água, fertilizantes e na produção de raízes de qualidade. Assim, o objetivo deste trabalho foi avaliar a produção de rabanete em função da frequência de irrigação e doses de nitrogênio em cobertura. Foram utilizadas sementes da cultivar Crimson Gigante, sendo o experimento conduzido num Argissolo de textura média, elevando a saturação de bases a $70 \%$. 0 delineamento foi o de blocos ao acaso, com quatro repetições em parcelas subdivididas, no esquema $2 \times 6$, sendo duas frequências de irrigação nas parcelas e seis doses de adubação nitrogenada em cobertura $(0$, $25,50,75,100$ e $125 \mathrm{~kg} \mathrm{ha}^{-1}$ de N) nas subparcelas. As frequências consistiram em irrigação uma vez por dia (em tempo total, de manhã, 06:15 - 07:15 h); e duas vezes por dia (50\% do tempo em cada período, de manhã, e à tarde, das 17:30 - 18:30 h), repondo a evapotranspiração diária da cultura, obtida através de lisímetros de pesagem. A colheita foi realizada aos 30 dias após a semeadura. A massa de raízes com defeitos $\left(11.105,4 \mathrm{~kg} \mathrm{ha}^{-1}\right)$ foi superior à de raízes comerciais $\left(1.658,2 \mathrm{~kg} \mathrm{ha}^{-1}\right)$. A irrigação duas vezes ao dia (manhã e tarde) e a aplicação de doses de $\mathrm{N}$ até $100 \mathrm{~kg} \mathrm{ha}^{-1}$ propiciaram maior área foliar, matéria seca de raízes, da parte aérea e total das plantas, porém não proporcionou ganho na produção de raízes comerciais.

Palavras-chave: evapotranspiração; Raphanus sativus L.; temperatura; turno de rega.

Watering frequency and nitrogen fertilization in radish production in the Mato Grosso northeast region, Brazil

\begin{abstract}
The Mato Grosso northeast, in Brazil, is characterized by presenting reference evapotranspiration above 4.0 $\mathrm{mm}$ day $^{-1}$. This high water demand indicates that the frequency of irrigation and the amount of $\mathrm{N}$ supplied to the radish crop can influence water saving, fertilizer and quality root production. Thus, the aim this paper was to evaluate the radish production as a function of the irrigation daily frequency and nitrogen rates in coverage. Seeds of the 'Crimson Gigante' radish cultivar were used, and the experiment was conducted in a medium texture Argisol, increasing the base saturation to $70 \%$. The experimental design was a randomized complete block, with four replications in split plots, in the $2 \times 6$ scheme, being two irrigation frequencies in the plots and six nitrogen fertilization rates $\left(0,25,50,75,100\right.$ and $125 \mathrm{~kg} \mathrm{ha}^{-1}$ of N) in the subplots. The frequencies consisted of irrigation once a day (in total time, in the morning, 6:15 - 7:15 am); and twice a day (50\% of the time in each period, in the morning, and in the afternoon, 5:30 - 6:30 p.m.), respectively, restituting the crop daily evapotranspiration, obtained by weighing lysimeters. The harvest was accomplished at 30 days after 'sowing. The defects roots production (11105.4 $\left.\mathrm{kg} \mathrm{ha}^{-1}\right)$ was higher than the commercials roots productivity $\left(1658.2 \mathrm{~kg} \mathrm{ha}^{-1}\right)$. The irrigation twice a day (morning and afternoon) and the application of $\mathrm{N}$ rates up to $100 \mathrm{~kg}$ ha- 1 provided greater leaf area, dry matter of roots, aerial part and total plants, but did not provide gain in the production of commercial roots.

Keywords: evapotranspiration; Raphanus sativus L.; temperature; irrigation interval.
\end{abstract}




\section{Introdução}

O rabanete (Raphanus sativus L.) é uma olerícola de ciclo curto, fundamental na diversificação da produção e rotação de culturas em áreas hortícolas. Em condições favoráveis, da semeadura à colheita, não leva mais do que 30 dias (PEDÓ et al., 2014; VICIEDO et al., 2017). Apesar das áreas produtoras serem relativamente pequenas, o rabanete é consumido em várias regiões do Brasil. A sua importância na alimentação, deve-se sobretudo à elevada concentração de sólidos solúveis, carboidratos, ácido fólico, vitaminas $A, C, B 1, B 2, B 6$, dentre outras substâncias antioxidantes (AYUB et al., 2013; GOUVEIA, 2016).

Dentre os fatores limitantes na produção de rabanete, atenção especial deve ser dada à frequência de irrigação e à adubação nitrogenada (BREGONCl et al., 2008; THOMSEN et al., 2016). Informações sobre o fornecimento de nitrogênio em culturas de ciclo de vida curto, como o rabanete são escassos (COUTINHO NETO et al., 2010). Na planta, o nitrogênio tem função em processos fisiológicos e bioquímicos, como fotossíntese, respiração e formação de biomoléculas, tais como aminoácidos e proteínas, ATP, NADH, clorofila, vitaminas e inúmeras enzimas (CORTEZ, 2009; CASTRO et al., 2016).

O nitrogênio é o nutriente mais requerido pelo rabanete, e o seu fornecimento não é totalmente suprido pela mineralização da matéria orgânica, por deixar poucos restos culturais no solo (CORTEZ, 2009; QUADROS et al., 2010). Oliveira et al. (2014) concluíram que a dose de nitrogênio de máxima eficiência para a massa do tubérculo de rabanete foi de 140,65 kg $\mathrm{ha}^{-1}$, sendo essa demanda a curto prazo.

A sustentabilidade no cultivo requer economia de insumos (REIS et al., 2012). Assim, o fornecimento de doses adequadas, visando minimizar perda de nutrientes é fundamental. Dentre as principais perdas, destacam-se a lixiviação e a volatilização do nitrogênio. No solo, o nitrogênio pode se transformar de $\mathrm{NH}_{4}{ }^{+}$ (amônio) para $\mathrm{NH}_{3}$ (amônia), quando, por exemplo, aplicado em solo seco (SILVA et al., 2017a), o que torna importante a umidade do solo durante a aplicação.

A deficiência de $\mathrm{N}$ dificilmente poderá ser corrigida durante o ciclo do rabanete, afetando negativamente a produção da parte aérea e produtividade de raízes (COUTINHO NETO et al., 2010; PEDÓ et al., 2014; SANTOS et al., 2016). Por outro lado, o excesso de nitrogênio $\left(\mathrm{NH}_{4}{ }^{+}\right)$, na concentração de até $30 \mathrm{mmol} \mathrm{L}^{-1}$ de solução, diminui a fotossíntese, transpiração e condutância estomática e, consequentemente, a matéria seca de raízes e da parte aérea (VICIEDO et al., 2017). São poucos os estudos que relacionam adubação nitrogenada e manejo de irrigação na cultura do rabanete, para obtenção de máximo rendimento.

O manejo da irrigação no rabanete pode ser feito através de reposição da evapotranspiração da cultura (ETc), determinada por meio de evaporímetros como o tanque classe A, ou através de lisímetros. A necessidade hídrica, expressa pelo coeficiente de cultivo $(\mathrm{kc})$ varia rapidamente, em poucos dias, em razão do curto ciclo (ALVES et al., 2017). No caso do rabanete, pode ser vantajosa a utilização de frequências de irrigação em diferentes horários, visando maior eficiência no uso da água e menor estresse hídrico das plantas em horários mais quentes.

O estresse hídrico e oscilações bruscas no teor de umidade do solo podem influenciar na morfologia e fisiologia de raízes, provocando rachaduras nas mesmas e redução na produtividade comercial (SILVA et al., 2017b). Recomenda-se que a umidade do solo esteja próxima à capacidade de campo (BREGONCl et al., 2008; AKRAM et al., 2015), ao longo de todo o ciclo.

O turno de rega, a irrigação total necessária e o fornecimento de nitrogênio devem considerar a textura e a capacidade de retenção de água do solo. Há evidências de que o horário de irrigação, matutino ou vespertino, possa maximizar ou minimizar perdas de água por evaporação, percolação profunda e lixiviação do $\mathrm{N}$ aplicado e, por consequência, influenciar na evapotranspiração, produção e qualidade das raízes.

Como a parte comercial da planta situa-se na camada subsuperficial, o rendimento do rabanete pode ser influenciado pelas condições nutricionais e físico-hídricas do solo (SILVA; SILVEIRA, 2012), sendo necessárias pesquisas sobre o tema. Assim, o objetivo deste trabalho foi avaliar a produção de rabanete em função da frequência de irrigação e doses de nitrogênio em cobertura.

\section{Material e Métodos}

O experimento foi conduzido num Argissolo Vermelho Amarelo distrófico, de textura média em Confresa, Mato Grosso, em área localizada a 1039'54" sul, 51ㅇ' 47" oeste, 
altitude de 214 metros. O clima na região é do tipo Aw, caracterizado por uma estação chuvosa, de outubro a abril, e uma estação seca, de maio a setembro (SOUZA et al., 2013). A temperatura média diária e as médias das temperaturas mínima, instantânea e máxima horária, durante o período experimental, são apresentadas na Figura 1.

Figura 1. Temperatura média diária do ar (A) e horária (B) durante o período experimental (22/08 a 22/09/2014), Confresa, MT, Brasil.

A.

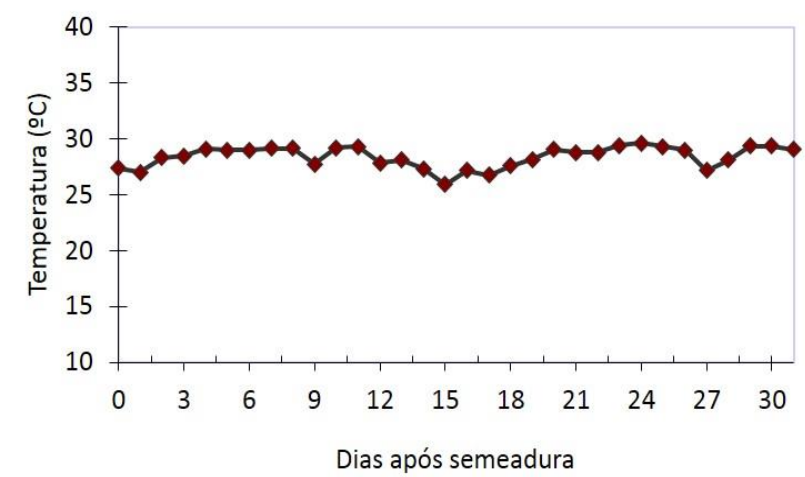

Fonte: INMET, 2014.

Os valores iniciais dos atributos químicos do solo, na camada de 0 a $20 \mathrm{~cm}$, foram: $\mathrm{Ca}^{2+}=$ $2,4 \mathrm{cmol}_{\mathrm{c}} \mathrm{dm}^{-3} ; \mathrm{Mg}^{2+}=0,8 \mathrm{cmol}_{\mathrm{c}} \mathrm{dm}^{-3} ; \mathrm{K}^{+}=0,32$ $\mathrm{cmol}_{\mathrm{c}} \mathrm{dm}^{-3} ; \mathrm{Al}^{3+}=0,5 \mathrm{cmol}_{\mathrm{c}} \mathrm{dm}^{-3} ; \mathrm{H}+\mathrm{Al}=4,6 \mathrm{cmol}_{\mathrm{c}}$ $\mathrm{dm}^{-3} ; \mathrm{P}_{\text {(Melich) }}=1,5 \mathrm{mg} \mathrm{dm}^{-3} ; \mathrm{S}=2,8 \mathrm{mg} \mathrm{dm}^{-3} ; \mathrm{Na}^{+}=$ $0,087 \mathrm{cmol}_{\mathrm{c}} \mathrm{dm}^{-3} ; \mathrm{Zn}=1,3 \mathrm{mg} \mathrm{dm}^{-3} ; \mathrm{B}=0,19 \mathrm{mg}$ $\mathrm{dm}^{-3} ; \mathrm{Cu}=2,3 \mathrm{mg} \mathrm{dm}^{-3} ; \mathrm{Fe}=253 \mathrm{mg} \mathrm{dm}^{-3}$ e $\mathrm{Mn}=$ $29 \mathrm{mg} \mathrm{dm}^{-3} ;$ CTC $=8,21 \mathrm{cmol}_{\mathrm{c}} \mathrm{dm}^{-3} ; \mathrm{V}=43,93 \% ; \mathrm{m}$ $=12,44 \% ; \mathrm{MO}=16 \mathrm{~g} \mathrm{dm}^{-3} ; \mathrm{pH}_{\mathrm{CaCl}}=4,5 ; \mathrm{e} \mathrm{N}-$ orgânico estimado em $0,8 \mathrm{~g} \mathrm{dm}^{-3}$.

O preparo do solo foi realizado após distribuir calcário dolomítico, incorporando-o ao solo, para elevar a saturação de bases a $70 \%$, conforme recomendação de Ribeiro et al. (1999). A adubação de fundação consistiu na aplicação, em antecedência à semeadura, de $10,23 \mathrm{~g} \mathrm{~m}^{-2}$ de $\mathrm{KCl}$ e $200 \mathrm{~g} \mathrm{~m}^{-2}$ de superfosfato simples.

Foram preparados 16 canteiros de $4,2 \mathrm{~m} \mathrm{x}$ $1,0 \mathrm{~m} \times 0,2 \mathrm{~m}$ de altura. Cada canteiro foi dividido em três subparcelas de 1,2 $\mathrm{m}$ de comprimento e 1,0 m de largura, deixando entre subparcelas um carreador de 0,3 m de largura, para realização dos tratos culturais. A semeadura da cultivar Crimson Gigante foi realizada em cinco linhas, espaçadas em 0,20 m entre si. Dez dias após a semeadura, realizou-se o desbaste, deixando cerca de 20 plantas por metro linear.

O delineamento experimental foi o de blocos casualizados, com quatro repetições, em parcelas subdivididas, no esquema $2 \times 6$. Os tratamentos primários foram duas frequências de
B.

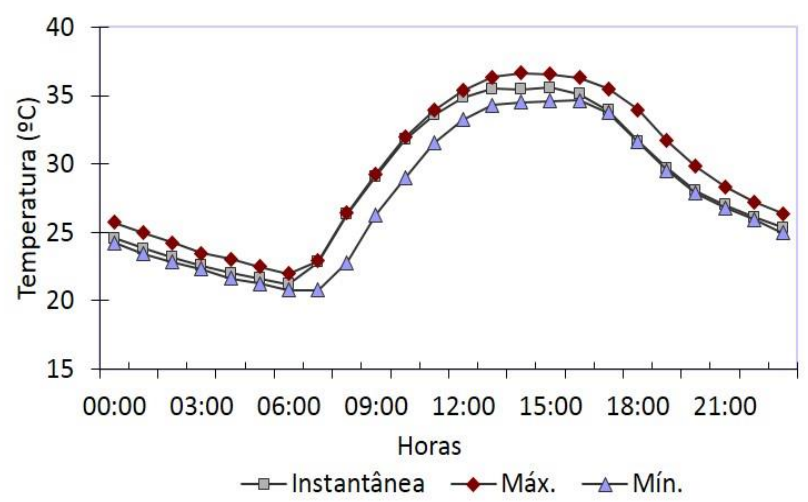

irrigação por microaspersão: uma vez por dia, de manhã (06:15 às 07:15 h), aplicando toda a lâmina de irrigação; e duas vezes por dia, aplicando $50 \%$ da lâmina de manhã e, os outros $50 \%$, à tarde (17:30 às 18:30 h).

Os tratamentos secundários consistiram de seis doses de nitrogênio em cobertura: 0 (sem adubação), 25, 50, 75, 100 e $125 \mathrm{~kg} \mathrm{ha}^{-1}$, em uma única dosagem, aos 10 dias após a semeadura. $\mathrm{A}$ fonte de nitrogênio utilizada foi a ureia, $45 \%$ de $\mathrm{N}$. As doses de $\mathrm{N}$ proporcionais à área de cada subparcela foram diluídas em 4,0 L de água e distribuídas por meio de regador.

O turno de rega diário foi igual em toda a área experimental até 10 dias após a semeadura. A partir desta fase, foram aplicados os tratamentos primários, fazendo-se o controle da lâmina de irrigação total necessária e do tempo de irrigação, por meio de seis lisímetros de pesagem, com plantas de rabanete e capacidade de $18 \mathrm{~L}$ de solo.

Os lisímetros foram preenchidos com o mesmo solo dos canteiros. Na base, utilizou manta geotêxtil e camada de $1,0 \mathrm{~cm}$ de areia fina. Fez-se o acondicionamento do solo, de forma homogênea, obtendo o mesmo peso dos lisímetros após o preenchimento. Posteriormente, os lisímetros foram saturados por capilaridade, imergindo-os num recipiente com água até a metade de sua altura. Em seguida, foram dispostos numa bancada para 
drenagem do excesso de água, sendo a superfície do solo vedada com filme plástico para impedir evaporação. Finalmente, determinou-se a umidade na capacidade de campo $\left(\theta_{\mathrm{cc}}=0,2873\right.$ $\mathrm{cm}^{3} \mathrm{~cm}^{-3}$ ) utilizando o método gravimétrico, conforme metodologia de Casaroli e Jong van Lier (2008).

A massa de solo na umidade de capacidade de campo $\left(M_{\theta c c}\right)$ e na umidade atual $\left(M_{\theta a t u a l}\right)$ foi obtida por meio de balança com capacidade $40.000 \mathrm{~g}$ e precisão de $5,0 \mathrm{~g}$, no local do experimento. Os lisímetros foram colocados em trincheira, na área experimental, ficando a superfície do solo no mesmo nível dos canteiros.

A evapotranspiração da cultura foi determinada através da Eq. 1, considerando massa específica da água igual a $1,0 \mathrm{~kg} \mathrm{~L}^{-1}$ :

$$
\mathrm{ETc}=4 \cdot\left(\frac{\mathrm{M}_{\theta \mathrm{cc}}-\mathrm{M}_{\text {Oatual }}}{\pi \cdot \mathrm{D}^{2}}\right)
$$

Eq. 1

em que: ETc é a evapotranspiração da cultura $(\mathrm{mm})$ entre duas regas consecutivas; $M_{\theta c c}$ é a massa média de seis lisímetros + solo na umidade de capacidade de campo + planta de rabanete $(\mathrm{kg}) ; M_{\theta c c}$ é a massa média dos lisímetros + solo na umidade atual + planta de rabanete $(\mathrm{kg})$; e D é o diâmetro dos lisímetros de pesagem, igual a 0,30 m, na altura do nível do solo.

O manejo diário da irrigação consistia em pesagem dos lisímetros em balança eletrônica, com capacidade de $40 \mathrm{~kg}$ e precisão de $0,005 \mathrm{~kg}$, e reposição do volume de água evapotranspirado por meio de proveta, retornando o solo à umidade na capacidade de campo. O tempo de irrigação foi determinado através da Eq. 2:

$$
\mathrm{Ti}=\frac{60 \cdot \mathrm{ETc} \cdot \mathrm{A}_{\text {molhada }}}{\mathrm{q} \cdot \mathrm{N}_{\text {micro }}}
$$

Eq. 2

em que: Ti é o tempo de irrigação (min.); $A_{\text {molhada }}$ é a área total molhada $\left(\mathrm{m}^{2}\right)$ pelos emissores, considerando o alcance dos mesmos além do limite dos canteiros; q é a vazão média dos emissores $\left(L h^{-1}\right)$, medida em campo; e $N_{\text {micro }}$ é o número de emissores distribuídos na $\mathrm{A}_{\text {molhada }}$.

A colheita foi realizada aos 30 dias após a semeadura. Foram avaliados os seguintes parâmetros:

a) Número de folhas por planta (NF): contagem de folhas em oito plantas selecionadas ao acaso na área útil $\left(0,8 \mathrm{~m}^{2}\right)$ da subparcela. b) Área foliar $\left(\mathrm{AF}, \mathrm{cm}^{2}\right.$ planta $\left.{ }^{-1}\right)$ : foram recortados, em cada subparcela, quatro retângulos foliares de $2,0 \mathrm{~cm} \times 4,0 \mathrm{~cm}$, acompanhando a nervura central de folhas com idade mediana. Em seguida, os retângulos foram secos em estufa, pesados e determinada a área foliar (Eq. 3).

$$
\mathrm{AF}=\frac{\mathrm{MSF}}{\mathrm{MS}_{\mathrm{ret}}} \cdot \mathrm{A}_{\mathrm{ret}}
$$

Eq. 3

em que: MSF é a massa de matéria seca de folhas (g planta ${ }^{-1}$ ); $\mathrm{MS}_{\text {ret }}$ é a massa média dos quatro retângulos foliares secos, amostrados por tratamento $(\mathrm{g})$; e $\mathrm{A}_{\text {ret }}$ é a área do retângulo foliar $\left(\mathrm{cm}^{2}\right)$.

c) Diâmetro transversal de raízes ( $\mathrm{DC}, \mathrm{mm}$ ): medido com paquímetro digital, em oito raízes na subparcela.

d) Massa de matéria seca da parte aérea (MSPA) e de raízes (MSR), em g planta ${ }^{-1}$ : as oito plantas selecionadas na área útil foram separadas em parte aérea (folhas) e raízes. Posteriormente, foram lavadas e secas em estufa com circulação forçada de ar, a $70^{\circ} \mathrm{C}$, até atingir massa constante. Após a secagem, as amostras foram pesadas em balança de precisão de 0,01 g.

e) Massa de matéria seca total (MSTO, g planta $^{-1}$ ): soma das massas de matéria seca da parte aérea e de raízes.

f) Relação entre as massas de matéria seca de raízes e da parte aérea (MSR/MSPA);

g) Produtividade de raízes comerciais (PRC, kg ha $\left.{ }^{1}\right)$;

h) Massa de raízes rachadas (MRR, $\mathrm{kg} \mathrm{ha}^{-1}$ );

i) Produtividade total (PT, $\mathrm{kg} \mathrm{ha}^{-1}$ ): soma da PRC e MRR.

j) Rendimento de raízes comerciais (RRC, raízes $\left.\mathrm{kg}^{-1}\right)$ : é o número de raízes comerciais por quilograma, considerando a massa de oito raízes da área útil, conforme a Eq. 4.

$$
\mathrm{RRC}=\frac{1000}{\mathrm{MRC}}
$$

Eq. 4

em que: MRC é a massa média das raízes comerciais (g raiz ${ }^{-1}$ ).

k) Teor de nitrogênio foliar (TNF): conforme metodologia de Miyazawa et al. (2009), em g kg ${ }^{-1}$ de matéria seca.

Os valores dos parâmetros avaliados foram submetidos ao teste de normalidade de Shapiro- 
Wilk $(p<0,05)$, com posterior transformação (raiz quadrada) dos dados que não seguem distribuição normal. Em seguida, procedeu-se a análise de variância, a 0,01 de significância, sendo utilizado o software SISVAR (FERREIRA, 2011). Os dados referentes às doses de nitrogênio foram analisados por meio de equações de regressão. $\mathrm{A}$ seleção dos modelos de equação foi baseada na significância do teste $\mathrm{F}$ e do modelo de equação, e no maior valor de coeficiente de determinação $\left(R^{2}\right)$. As frequências de irrigação foram comparadas por meio teste de Tukey $(p<0,05)$, assim como as doses de $\mathrm{N}$, nas situações em que as equações lineares e quadráticas não tiveram significância.

\section{Resultados e Discussão}

Durante o período de condução do experimento não houve precipitação pluvial, sendo o suprimento de água às plantas apenas via irrigação. A análise de variância (Tabela 1) indicou efeito significativo das frequências de irrigação $(p<0,01)$ na área foliar $(A F)$, nas massas de matéria seca de raízes (MSR), da parte aérea (MSPA) e total (MSTO) das plantas. As frequências de irrigação não tiveram significância na produtividade de rabanete. Também não apresentaram efeito significativo no teor de $\mathrm{N}$ foliar, independentemente da dose de $\mathrm{N}$ aplicada.

As doses de adubação nitrogenada com ureia tiveram significância na $\operatorname{AF}(p<0,01)$, na MSR, MSPA, MSTO e produtividade comercial (PRC), a $5 \%$ de probabilidade pelo teste F. Somente houve interação significativa das frequências de irrigação $\mathrm{x}$ doses de $\mathrm{N}$ para a área foliar $(p<0,01)$.

Tabela 1. Resumo da análise de variância do número de folhas por planta (NF), área foliar (AF, $\mathrm{cm}^{2}$ planta $\left.{ }^{-1}\right)$, diâmetro de raízes (DR, $\mathrm{mm}$ ), massas de matéria seca de raízes (MSR, g planta ${ }^{-1}$ ), da parte aérea (MSPA, $g$ planta $^{-1}$ ) e total (MSTO, g planta ${ }^{-1}$ ), relação das massas de raízes e parte aérea (MSR/MSPA), produtividade comercial (PRC, $\left.\mathrm{kg} \mathrm{ha}^{-1}\right)$, massa de raízes rachadas $\left(\mathrm{MRR}, \mathrm{kg} \mathrm{ha}^{-1}\right)$, produtividade total (PT, $\mathrm{kg} \mathrm{ha}^{-1}$ ), rendimento de raízes comerciais ( $R R C$, raízes $\mathrm{kg}^{-1}$ ) e teor de nitrogênio foliar (TNF, $\mathrm{g} \mathrm{kg}^{-1}$ de matéria seca) da cultura do rabanete, cv. Crimson Gigante, em função de frequências de irrigação e doses de nitrogênio. Confresa-MT, Brasil, 2014.

\begin{tabular}{|c|c|c|c|c|c|c|c|}
\hline \multirow[b]{2}{*}{$\begin{array}{l}\text { Parâmetros } \\
\text { avaliados }\end{array}$} & \multicolumn{4}{|c|}{ Quadrado Médio } & \multirow[b]{2}{*}{$\begin{array}{c}\mathrm{CV}_{\text {Irrigação }} \\
(\%)\end{array}$} & \multirow[b]{2}{*}{$\begin{array}{l}\mathrm{CV}_{\text {Nitrogênio }} \\
(\%)\end{array}$} & \multirow[b]{2}{*}{$\begin{array}{l}\text { Média } \\
\text { geral }^{1}\end{array}$} \\
\hline & Blocos & Irrigação (I) & $\begin{array}{l}\text { Nitrogênio } \\
\text { (N) }\end{array}$ & $\mathrm{I} \times \mathrm{N}$ & & & \\
\hline NF & $0,52 \mathrm{~ns}$ & $\begin{array}{c}4,40 \mathrm{~ns} \\
21902209,35^{*}\end{array}$ & $0,33 \mathrm{~ns}$ & $0,30 \mathrm{~ns}$ & 17,10 & 10,72 & 5,10 \\
\hline$A F$ & $138629,87 \mathrm{~ns}$ & $*$ & $607408,41^{* *}$ & $807750,54 * *$ & 14,30 & 15,24 & 2196,85 \\
\hline $\mathrm{DR}$ & $0,104 \mathrm{~ns}$ & $0,164 \mathrm{~ns}$ & $0,041 \mathrm{~ns}$ & $0,040 \mathrm{~ns}$ & $5,16^{\mathrm{sW}}$ & $4,24^{\mathrm{SW}}$ & 30,91 \\
\hline MSR & $0,018 \mathrm{~ns}$ & $3,326 * *$ & $0,043^{*}$ & $0,008 \mathrm{~ns}$ & $8,44^{\mathrm{sW}}$ & $8,14^{\mathrm{sW}}$ & 2,11 \\
\hline MSPA & $0,016 \mathrm{~ns}$ & $3,359 * *$ & $0,044^{*}$ & $0,009 \mathrm{~ns}$ & $8,17^{\mathrm{sW}}$ & $8,10^{\mathrm{sW}}$ & 2,10 \\
\hline MSTO & $0,034 \mathrm{~ns}$ & $6,693^{* *}$ & $0,087^{*}$ & $0,017 \mathrm{~ns}$ & $8,29^{\mathrm{SW}}$ & $8,13^{\mathrm{sW}}$ & 4,21 \\
\hline MSR/MSPA & $0,000028 \mathrm{~ns}$ & $0,000056 \mathrm{~ns}$ & $0,000021 \mathrm{~ns}$ & $0,000021 \mathrm{~ns}$ & $0,53^{\mathrm{sW}}$ & $0,46^{\mathrm{sW}}$ & 1,00 \\
\hline PRC & $\begin{array}{c}145,501 \mathrm{~ns} \\
9884642,30\end{array}$ & 82,162 ns & $\begin{array}{c}365,202 * \\
2032012,35\end{array}$ & $\begin{array}{c}147,089 \text { ns } \\
3583860,76\end{array}$ & $22,93^{\mathrm{sW}}$ & $26,14^{\mathrm{sw}}$ & 1658,23 \\
\hline MRR & $\begin{array}{c}\text { ns } \\
4087442,79\end{array}$ & 16372,36 ns & $\begin{array}{c}\text { ns } \\
5663126,57\end{array}$ & $\begin{array}{c}\text { ns } \\
8156807,17\end{array}$ & 38,73 & 22,64 & 11105,44 \\
\hline PT & ns & $165697,33 \mathrm{~ns}$ & ns & ns & 31,07 & 21,38 & 12763,67 \\
\hline RRC & $0,427 \mathrm{~ns}$ & $0,335 \mathrm{~ns}$ & $0,122 \mathrm{~ns}$ & $0,681 \mathrm{~ns}$ & $9,07^{\mathrm{sW}}$ & $11,95^{\mathrm{sW}}$ & 38,12 \\
\hline TNF & $0,240 \mathrm{~ns}$ & $0,849 \mathrm{~ns}$ & $0,260 \mathrm{~ns}$ & $0,025 \mathrm{~ns}$ & $8,43^{\mathrm{sW}}$ & $10,68^{\mathrm{sw}}$ & 18,70 \\
\hline
\end{tabular}

** Significativo a $1 \%$ de probabilidade, pelo teste $\mathrm{F} ;{ }^{*}$ Significativo a $5 \%$ de probabilidade, pelo teste $\mathrm{F}$; NS - Não significativo; GL - Grau de liberdade; CV - Coeficiente de variação; SW - Os dados originais não seguem distribuição normal pelo teste de Shapiro-Wilk $(p<0,05)$ e, então procedeu-se a transformação de dados (raiz quadrada). ${ }^{1}$ Média dos dados originais.

Comparando as frequências de irrigação, verificou-se que a irrigação no rabanete duas vezes ao dia (manhã e tarde) apresentou maiores valores para as variáveis área foliar e 
massas de matéria seca de raízes, da parte aérea e total das plantas (Tabela 2). O parcelamento da lâmina de irrigação em dois períodos comparada à irrigação apenas de manhã proporcionou AF, MSR, MSPA e MSTO superiores em 1,88; 2,08; 2,11 e 2,09 vezes, respectivamente. Com base nestes resultados, uma hipótese é que a irrigação apenas de manhã propicia maior oscilação da umidade do solo a partir da capacidade de campo, na camada de solo explorada pelo sistema radicular, tornando o solo mais seco e, consequentemente, murchamento e menor evapotranspiração no horário da tarde, com redução no crescimento das plantas. Bregonci et al. (2008) recomenda que a umidade do solo seja mantida próxima à capacidade de campo, uma vez que o fator de disponibilidade para a cultura do rabanete oscila de 0,30 a 0,45, conforme a textura do solo (MAROUELLI et al., 2017). Conforme Alves et al. (2017), as fases II e III, de desenvolvimento da área foliar da cultura e formação da raiz tuberosa, são as que apresentam maior demanda de água e, portanto, são as mais críticas quando se realiza a irrigação apenas de manhã.

Tabela 2. Área foliar (AF, $\mathrm{cm}^{2}$ planta $^{-1}$ ), massa de matéria seca de raízes (MSR), da parte aérea (MSPA) e total (MSTO), em g planta ${ }^{-1}$, de plantas de rabanete cv. Crimson Gigante, em função de frequências de irrigação e doses de nitrogênio. Confresa-MT, Brasil, 2014.

\begin{tabular}{|c|c|c|c|c|c|c|c|c|c|}
\hline \multirow{2}{*}{$\begin{array}{l}\text { Parâmetr } \\
\text { o avaliado }\end{array}$} & \multirow{2}{*}{$\begin{array}{l}\text { Frequência de } \\
\text { irrigação }\end{array}$} & \multicolumn{6}{|c|}{ Doses de $\mathrm{N}\left(\mathrm{kg} \mathrm{ha}^{-1}\right)$} & \multirow{2}{*}{ Média } & \multirow{2}{*}{ DMS } \\
\hline & & 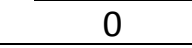 & 25 & 50 & 75 & 100 & 125 & & \\
\hline \multirow{3}{*}{$\mathrm{AF}$} & Manhã & 1763,50 & 1007,40 & 1528,66 & 1418,24 & 1790,66 & 1619,66 & $1521,35 A$ & \multirow{3}{*}{$\begin{array}{c}316 \\
33\end{array}$} \\
\hline & Manhã & e 2546,37 & 3024,34 & 2657,78 & 2606,57 & 2531,25 & 3867,78 & ,35 & \\
\hline & Média: & 2154,93 & 2015,87 & 2093,22 & 2012,40 & 2160,95 & 2743,72 & 2196,85 & \\
\hline \multirow{3}{*}{ MSR } & Manhã & 1,10 & 1,06 & 1,43 & 1,38 & 1,67 & 1,51 & $1,36 \mathrm{~B}$ & \multirow{3}{*}{0,32} \\
\hline & Manhã & 2,68 & 2,71 & 2,80 & 2,85 & 3,16 & 2,87 & $2,84 \mathrm{~A}$ & \\
\hline & Média: & 1,89 & 1,89 & 2,12 & 2,12 & 2,42 & 2,19 & 2,11 & \\
\hline \multirow{3}{*}{ MSPA } & Manhã & 1,08 & 1,05 & 1,43 & 1,38 & 1,67 & 1,51 & $1,35 \mathrm{~B}$ & \multirow{3}{*}{0,31} \\
\hline & Manhã & 2,68 & 2,71 & 2,80 & 2,85 & 3,16 & 2,87 & $2,85 \mathrm{~A}$ & \\
\hline & Média: & 1,88 & 1,89 & 2,12 & 2,12 & 2,42 & 2,19 & 2,10 & \\
\hline \multirow{3}{*}{ MSTO } & Manhã & 2,18 & 2,12 & 2,86 & 2,78 & 3,36 & 3,04 & $2,72 \mathrm{~B}$ & \multirow{3}{*}{0,57} \\
\hline & Manhã & 5,38 & 5,44 & 5,62 & 5,70 & 6,32 & 5,74 & $5,70 \mathrm{~A}$ & \\
\hline & Média: & 3,78 & 3,78 & 4,24 & 4,24 & 4,84 & 4,39 & 4,21 & \\
\hline
\end{tabular}

Médias seguidas pela mesma letra na coluna, para o mesmo parâmetro avaliado, não diferem entre si, pelo teste de Tukey, a 5\% de probabilidade. DMS: Diferença Mínima Significativa

Devido às propriedades físicas do solo, como a textura média, a elevada taxa de infiltração básica $(49,16 \mathrm{~mm} / \mathrm{h})$ e umidade na capacidade de campo de apenas $0,2873 \mathrm{~cm}^{3} \mathrm{~cm}^{-3}$, possivelmente parte do $\mathrm{N}$ aplicado em cobertura, aos 10 dias após a semeadura, tenha sido perdido por lixiviação quando a irrigação foi realizada $100 \%$ de manhã. Tal perda se deve ao sistema radicular das plantas não apresentarem profundidade uniforme em toda a área, considerando que o molhamento pela microaspersão ocorre em área total.

A adubação nitrogenada influenciou a AF nas duas frequências de irrigação (Figura 2). Utilizando irrigação apenas de manhã, obteve-se AF de $1790,6 \mathrm{~cm}^{2}$ planta $^{-1}$ com a aplicação de 100 $\mathrm{kg} \mathrm{ha}^{-1}$ de N. Já no tratamento em que se utilizava irrigação de manhã e à tarde, a adubação com $125 \mathrm{~kg} \mathrm{ha}^{-1}$ de $\mathrm{N}$ resultou maior área de folhas por planta, de $3867,7 \mathrm{~cm}^{2}$, valor este pouco superior ao obtido com a aplicação de $25 \mathrm{~kg} \mathrm{ha}^{-1}$ de $\mathrm{N}$, de $3024,35 \mathrm{~cm}^{2}$ planta ${ }^{-1}$. Esses resultados diferem dos encontrados por Quadros et al. (2010), já que esses autores não verificaram efeito significativo das doses de N $(0 ; 30 ; 60 ; 120$; $240 \mathrm{~kg} \mathrm{ha}^{-1}$ de N) na área foliar de rabanete. Cortez (2009) avaliando duas cultivares de rabanete a doses de $\mathrm{N}$ e esterco bovino, verificou máxima AF com a aplicações de 154 e $180 \mathrm{~kg} \mathrm{ha}^{-1}$ de N. Não é possível estabelecer uma comparação direta dos resultados, uma vez que estes autores além de aplicarem as dosagens de $\mathrm{N}$, também aplicaram esterco bovino, com pequena mineralização durante o curto ciclo do rabanete. Com relação às olerícolas de raízes tuberosas, Aquino et al. (2006) obtiveram resposta linear da AF com a aplicação de N, mas no cultivo de beterraba. As massas de matéria 
seca de raízes, da parte aérea e total apresentaram resposta linear com o aumento das doses de nitrogênio (Figura 3). Com a dose de $125 \mathrm{~kg} \mathrm{~N} \mathrm{ha}^{-1}$, a MSR e a MSPA foram estimadas em 2,32 g planta $^{-1}$ cada uma. A produtividade comercial ótima foi estimada em $2123,77 \mathrm{~kg} \mathrm{ha}^{-1}$, com a dose de $50,34 \mathrm{~kg} \mathrm{ha}^{-1}$ de N. As doses acima de $75 \mathrm{~kg} \mathrm{ha}^{-1}$ não promoveram incrementos na produtividade comercial, estando acima da recomendação de Raij et al. (1997) para a produção de rabanete $\left(60 \mathrm{~kg} \mathrm{ha}^{-1}\right)$.

Figura 2. Área foliar (AF) de plantas de rabanete cv. Crimson Gigante, em função de doses de nitrogênio e frequências de irrigação, de manhã (A) e de manhã e à tarde (B). Confresa-MT, Brasil, 2014.

A.

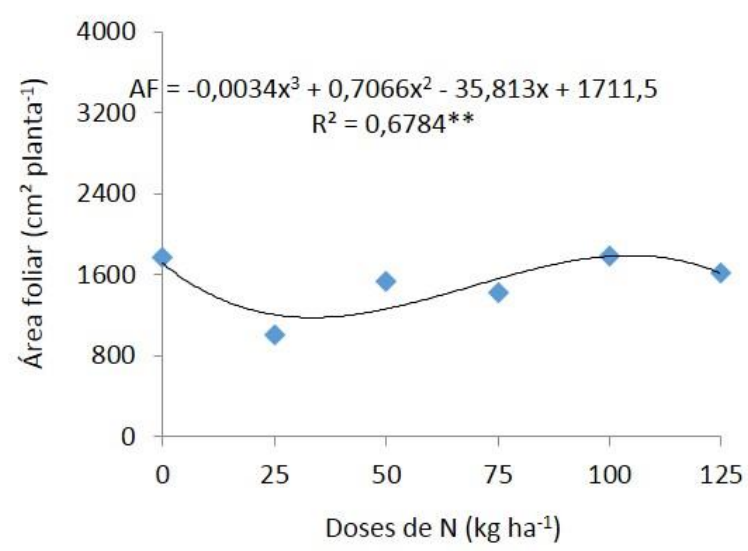

B.

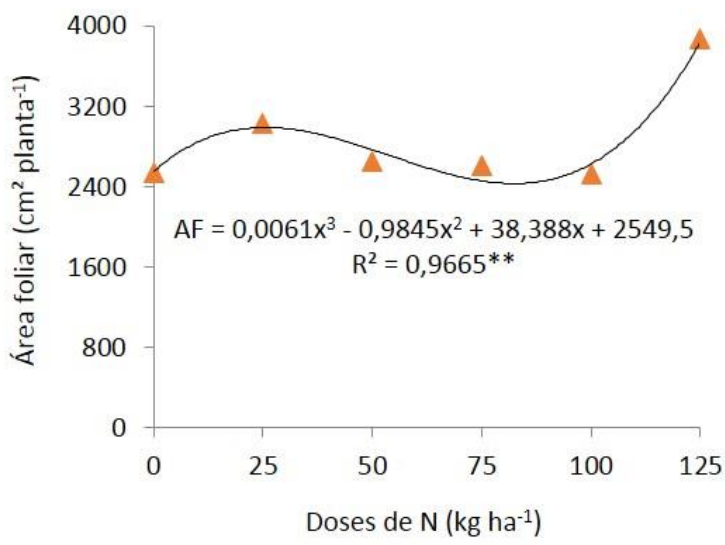

Figura 3. Massa de matéria seca de raiz (MSR), da parte aérea (MSPA), total (MSTO) e produtividade comercial (PRC) de plantas de rabanete cv. Crimson Gigante, em função de doses de nitrogênio. ConfresaMT, Brasil, 2014. 

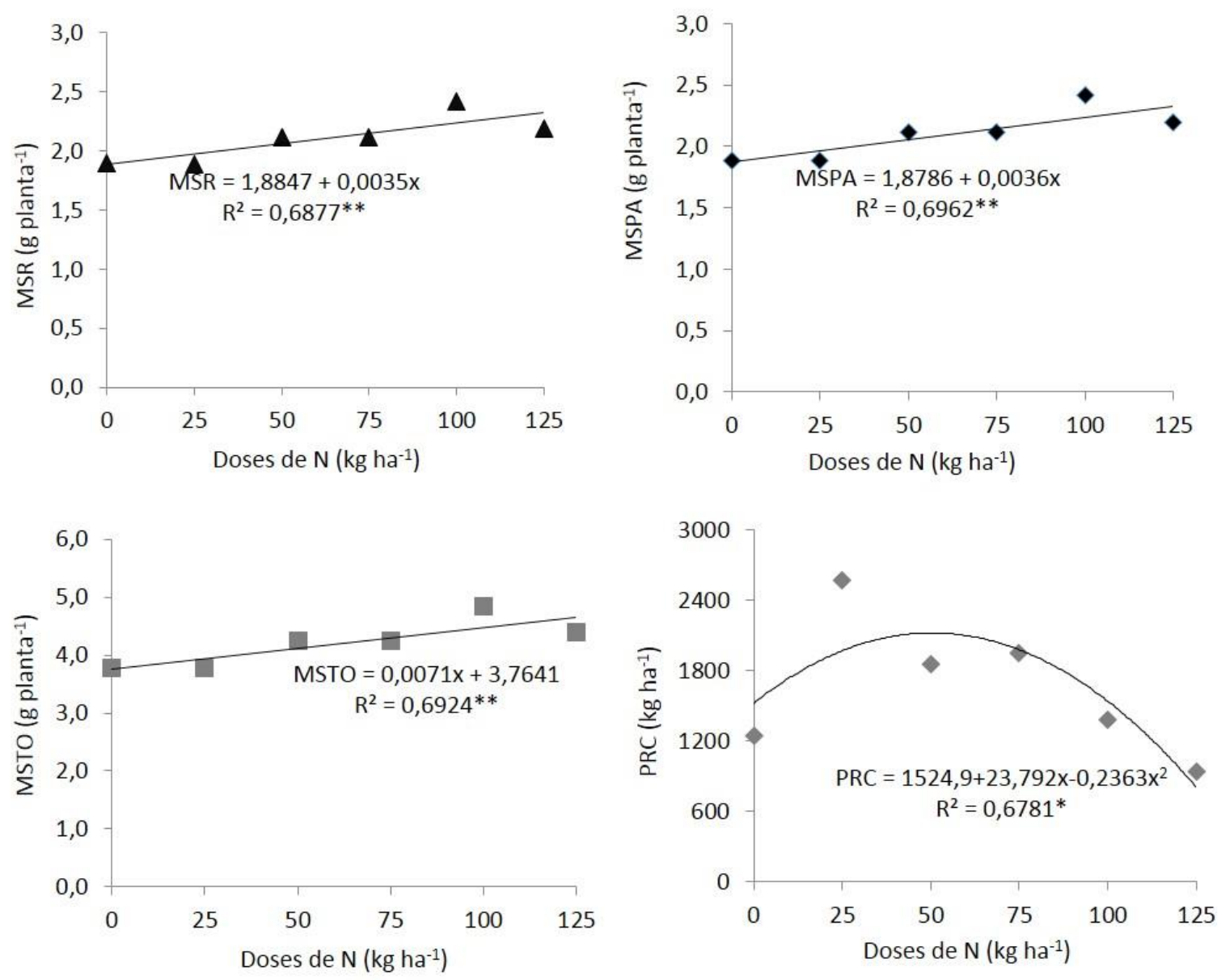

Dentre as variáveis analisadas, não houve efeito significativo de doses de $\mathrm{N}$ e frequências de irrigação no diâmetro de raízes. Este parâmetro apresentou valor médio de 30,9 $\mathrm{mm}$, aos 30 dias após a semeadura, considerado pequeno para a cultivar Crimson Gigante. Isso se deve provavelmente às condições meteorológicas da região não terem sido propícias, principalmente a temperatura, atingindo valores máximos de $35 \% \mathrm{C}$, encurtando o ciclo desta cultivar e causando diminuição no diâmetro das raízes. Apesar dessa cultivar ser recomendada para todo o Brasil, atenção especial deve ser dada à época de cultivo, preferencialmente nos meses de abril a agosto (TOPSEED, 2019).

Quadros et al. (2010) também não encontraram significância para o diâmetro de raízes em experimento com aplicação de $\mathrm{N}$ em cobertura no rabanete. E com relação à irrigação, Bregonci et al. (2008) não verificaram efeito de diferentes frequências de irrigação, em três fases fenológicas, no diâmetro transversal de raízes de rabanete.

Não houve significância dos tratamentos primários e secundários sobre a relação

MSR/MSPA, massa de raízes rachadas, produtividade total, rendimento de raízes comerciais e teor de $\mathrm{N}$ foliar. Os valores médios destes parâmetros foram 1,0; $11.105,44 \mathrm{~kg} \mathrm{ha}^{-1}$; $12.763,67 \mathrm{~kg} \mathrm{ha}^{-1} ; 38,11$ raízes $\mathrm{kg}^{-1}$ e $18,7 \mathrm{~g} \mathrm{~kg}^{-1}$, respectivamente. Estes resultados são coerentes aos obtidos por Cardoso e Hiraki (2001), uma vez que não obtiveram significância na produtividade comercial e de raízes rachadas, ao aplicarem doses de nitrogênio na forma nítrica. Cortez (2009) também não obteve efeito significativo das doses de $\mathrm{N}\left(0,60,120\right.$ e $\left.180 \mathrm{~kg} \mathrm{ha}^{-1}\right)$ sobre o teor de $\mathrm{N}$ foliar, ao aplicar as doses em combinação com esterco $\left(0,25,50\right.$ e $75 \mathrm{t} \mathrm{ha}^{-1} \mathrm{em}$ base seca) na cultura do rabanete.

Maiores valores da MSTO foram obtidos na dose de $100 \mathrm{~kg} \mathrm{ha}^{-1}$ de $\mathrm{N}$, não diferindo das doses de 50, 75 e $125 \mathrm{~kg} \mathrm{ha}^{-1}$ (Figura 4). Maiores acúmulos de MSR e MSPA também foram encontrados nessas mesmas doses, onde cada parâmetro constituiu aproximadamente $50 \%$ da MSTO. Com relação à produção de raízes rachadas, não houve diferença estatística entre as doses de $\mathrm{N}$, enquanto a produção de raízes comerciais foi maior na dose de $25 \mathrm{~kg} \mathrm{ha}^{-1}$ de $\mathrm{N}$. 
Figura 4. Partição da matéria seca (A) e produção de raízes comerciais e rachadas (B) de rabanete cv. Crimson Gigante, em função de doses de nitrogênio. Confresa-MT, Brasil, 2014.

A.

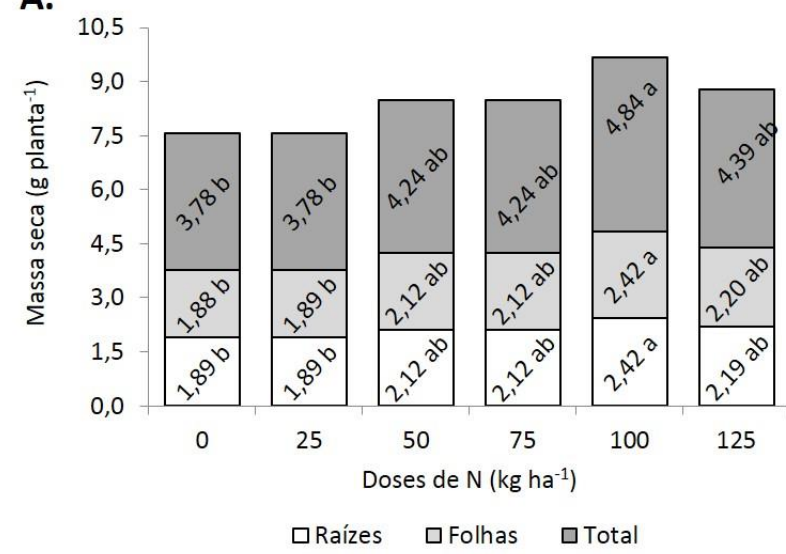

B.

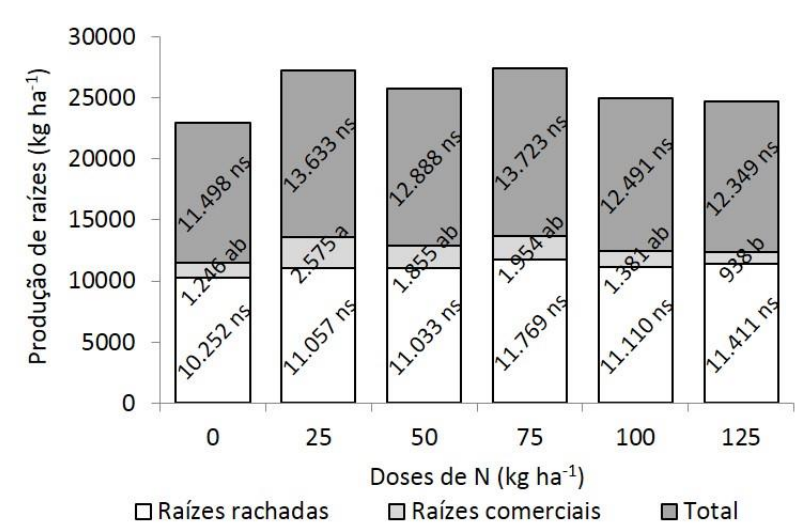

Médias seguidas pela mesma em cada parâmetro avaliado, não diferem entre as doses de N, pelo teste de Tukey, a 5\% de probabilidade.

A produtividade de raízes comerciais foi de apenas $13 \%$ e a massa de raízes rachadas $87 \%$, valor este explicado devido sobretudo às altas temperaturas durante o período experimental, o rápido crescimento do sistema radicular da cv. Crimson Gigante e as oscilações na umidade do solo durante o período diurno, fatores estes associados à rachadura das raízes (COSTA et al., 2006; SILVA et al., 2017b).

Costa et al. (2006) verificaram que a oscilação térmica no solo ocorre devido a elevadas temperaturas e à falta de cobertura morta no solo, o que favorece o rápido secamento da camada superficial, ocasionando rachaduras nas raízes. Silva et al. (2017b) constataram que as altas temperaturas e radiação solar em cultivo na primavera promoveram oscilações bruscas na umidade do solo entre os intervalos de irrigação, ocasionando maior quantidade de raízes rachadas, em comparação ao cultivo outono-inverno, de menor temperatura. Apesar dessa pesquisa ter sido conduzida no outono-inverno, a quantidade de raízes rachadas foi elevada, devido aos maiores picos de temperaturas registradas, em comparação ao experimento de Silva et al. (2017b). Cortez (2009) acrescenta que as rachaduras no rabenete podem ter causas de ordem genética, que no caso da cv. Crimson Gigante, a rápida expansão das raízes favorece as rachaduras e, consequentemente, as tornam inviáveis para comercialização.

Constatou-se que a irrigação duas vezes ao dia promoveu melhores resultados com a cultivar Crimson Gigante. Futuras pesquisas devem ser conduzidas sobre o tema, visando maior eficiência no uso da água e nutrientes, em diferentes locais.

\section{Conclusões}

A frequência de irrigação duas vezes ao dia, parcelando a lâmina de manhã e à tarde, proporcionou maior área foliar e matéria seca da parte aérea e das raízes de rabanete.

A produção de raízes comerciais não se diferiu com a adição de $\mathrm{N}$ ao solo, enquanto a matéria seca de folhas, raízes e total das plantas de rabanete foram maiores aplicando $100 \mathrm{~kg} \mathrm{ha}^{-1}$ de $\mathrm{N}$.

Nas condições edafoclimáticas do nordeste de Mato Grosso, cv. Crimson Gigante apresentou maior produção de raízes rachadas do que de raízes comerciais, independentemente da frequência de irrigação e dose de N.

\section{Referências}

AKRAM, N. A.; NOREEN, S.; NOREEN, T.; MUHAMMAD, A. Exogenous application of trehalose alters growth, physiology and nutrient composition in radish (Raphanus sativus L.) plants under water-deficit conditions. Revista Brasileira de Botânica, v. 38, n. 3, p. 431-439, 2015. http://dx.doi.org/10.1007/s40415-015-0149-7

ALVES, E. S.; LIMA, D. F.; BARRETO, J. A. S.; SANTOS, D. P. SANTOS, M. A. L. Determinação do coeficiente de cultivo para a cultura do rabanete através de lisimetria de drenagem. Irriga, v. 22, n. 1, p. 194-203, 2017. 
https://doi.org/10.15809/irriga.2017v22n1p194$\underline{203}$

AQUINO, L. A.; PUIATTI, M.; PEREIRA, P. R. G.; PEREIRA, F. H. F.; LADEIRA, I. R.; CASTRO, M. R. S. Produtividade, qualidade e estado nutricional da beterraba de mesa em função de doses de nitrogênio. Horticultura Brasileira, v. 24, n. 2, p. 199-203, 2006. https://doi.org/10.1590/S0102$\underline{05362006000200015}$

AYUB, R. A.; SPINARDI, B.; GIOPPO, M. Storage and fresh cut radish. Acta Scientiarum

Agronomy, Maringá, v. 35, n. 2, p. 241-245, 2013. https://doi.org/10.4025/actasciagron.v35i2.1546 $\underline{1}$

BREGONCI, I. S.; ALMEIDA, G. D.; BRUM, V. J.; ZINI JUNIOR, A; REIS, E. F. Desenvolvimento do sistema radicular do rabanete em condições de estresse hídrico. Idesia, v. 26, n. 1, p. 33-38, 2008. https://doi.org/10.4067/S0718-

$\underline{34292008000100005}$

CARDOSO, A. I. I.; HIRAKI, H. Avaliação de doses e épocas de aplicação de nitrato de cálcio em cobertura na cultura do rabanete. Horticultura Brasileira, v. 19, n. 3, p. 196-199, 2001.

https://doi.org/10.1590/S0102-

$\underline{05362001000300007}$

CASAROLI, D.; JONG VAN LIER, Q. de. Critérios para a determinação da capacidade de vaso. Revista Brasileira de Ciência do Solo, v. 32, n. 1, p. 59-66, 2008. https://doi.org/10.1590/S0100$\underline{06832008000100007}$

CASTRO, B. F.; SANTOS, L. G.; BRITO, C. F. B.; FONSECA, V. A.; BEBÉ, F. V. Produção de rabanete em função da adubação potássica e com diferentes fontes de nitrogênio. Revista de Ciências Agrárias, Lisboa, v. 39, n. 3, p. 341-348, 2016. https://doi.org/10.19084/RCA15131

CORTEZ, J. W. M. Esterco de bovino e nitrogênio na cultura de rabanete. 2009. 62 f. Dissertação (Mestrado em Produção Vegetal) - Universidade Estadual Paulista "Júlio de Mesquita Filho", Jaboticabal, 2009.

COSTA, C. C.; OLIVEIRA, C. D.; SILVA, C. J.; TIMOSSI, P. C; LEITE, I. C. Crescimento, produtividade e qualidade de raízes de rabanete cultivadas sob diferentes fontes e doses de adubos orgânicos. Horticultura Brasileira, v. 24, n. 1, p. 118-122, 2006.

https://doi.org/10.1590/S0102-

$\underline{05362006000100024}$

COUTINHO NETO, A. M.; ORIOLI JÚNIOR, V.; CARDOSO, S. S.; COUTINHO, E. L. M. Produção de matéria seca e estado nutricional do rabanete em função da adubação nitrogenada e potássio. Nucleus, v. 7, n. 2, p. 105-114, 2010.

FERREIRA, D. F. SISVAR: a computer statistical analysis system. Ciência e Agrotecnologia, v. 35, n. 6, p. 1039-1042, 2011.

https://doi.org/10.1590/S1413$\underline{70542011000600001}$

GOUVEIA, A. M. S. Adubação potássica na produção e qualidade pós-colheita do rabanete. 2016. 88 f. Dissertação (Mestrado em Agronomia - Horticultura) - Faculdade de Ciências Agronômicas, Universidade Estadual Paulista, Botucatu, 2016.

Instituto Nacional de Meteorologia (INMET). Estações automáticas. Brasília: INMET, 2014. Disponível em:

http://www.inmet.gov.br/portal/index.php?r=est acoes/estacoesAutomaticas. Acesso em: $08 \mathrm{dez}$. 2014.

MAROUELLI, W. A.; SILVA, H. R. da; SILVA, W. L. de C. e. Irrigação por aspersão em hortaliças: qualidade da água, aspectos do sistema e método prático de manejo. 4. ed. rev. e ampliada. Brasília, DF: Embrapa Informação Tecnológica, 2017. 200 p.

MIYAZAWA, M.; PAVAN, M. A.; MURAOKA, T.; CARMO, C. A. F. S.; MELO, W. J. Analise química de tecido vegetal. In: SILVA, F. C. Manual de análises química de solos, plantas e fertilizantes. Brasília: Embrapa, 2009. p. 192 -233.

OLIVEIRA, G. Q.; BÍSCARO, G. A.; MOTOMIYA, A. V. A.; JESUS, M. P.; VIEIRA FILHO, P. S. Aspectos produtivos do rabanete em função da adubação nitrogenada com e sem hidrogel. Journal of Agronomic Sciences, v. 3, n. 1, p. 89-100, 2014.

PEDÓ, T.; AUMONDE, T. Z.; MARTINAZZO, E. G.; VILLELA, F. A.; LOPES, N. F.; MAUCH, C. R. Análise de crescimento de plantas de rabanete 
submetidas a doses de adubação nitrogenada. Bioscience Journal, v. 30, n. 1, p. 1-7, 2014.

QUADROS, B. R.; SILVA, E. S.; BORGES, L. S.; MOREIRA, C. A.; MORO, A. L.; BOAS, R. L. V. Doses de nitrogênio na produção de rabanete fertirrigado e determinação de clorofila por medidor portátil nas folhas. Irriga, v. 15, n. 4, p. 353-360, 2010.

https://doi.org/10.15809/irriga.2010v15n4p353

RAIJ, B. VAN.; CANTARELLA, H.; QUAGGIO, J. A.; FURLANI, A. M. C. Recomendações de adubação e calagem para o Estado de São Paulo. 2. ed. Campinas, SP: Instituto Agronômico de Campinas, 1997. 285 p.

REIS, J. M. R.; RODRIGUES, J. F.; REIS, M. A. Combinação de fertilizantes na produção de rabanete. Enciclopédia Biosfera, v. 8, n. 15, p. 438, 2012.

RIBEIRO, A. C.; GUIMARÃES, P. T. G.; ALVAREZ, V. V. H. Recomendação para uso de corretivos e fertilizantes em Minas Gerais: 5ạ aproximação. Viçosa: UFV, 1999. 359 p.

SANTOS, J. L.; FERNANDES, C. A. F.; OLIVEIRA, L. S.; JESUS, C. M.; PORTO, J. S.; REBOUÇAS, T. N. H. Use of mulches and their effects on the radish crop. Revista Brasileira de Engenharia Agrícola e Ambiental, v. 20, n. 11, p. 955-959, 2016.

https://doi.org/10.1590/1807-

1929/agriambi.v20n11p955-959

SILVA, A. F. A.; SOUZA, Ê. G. F.; BARROS JÚNIOR, A. P.; BEZERRA NETO, F.; SILVEIRA, L. M. Desempenho agronômico do rabanete adubado com Calotropis procera (Ait.) $\mathrm{R}$. Br. em duas épocas de cultivo. Revista Ciência Agronômica, v. 48, n. 2, p. 328-336, 2017b.

https://doi.org/10.5935/1806-6690.20170038

SILVA, C. R. M.; SILVEIRA, M. H. D. Fertirrigação da cultura do rabanete com diferentes dosagens de nitrogênio. Enciclopédia Biosfera, v. 8, n. 15, p. 947-953, 2012.

SILVA, D. F.; PEGORARO, R. F.; MAIA, V. M.; KONDO, M. K.; SOUZA, G. L. O. D.; MOTA, M. F. C. Volatilização de amônia do solo após doses de ureia com inibidores de urease e nitrificação na cultura do abacaxi. Revista Ceres, v. 64, n. 3, p.
327-335, 2017a. https://doi.org/10.1590/0034$\underline{737 \times 201764030014}$

SOUZA, A. P.; MOTA, L. L.; ZAMADEI, T.; MARTIM, C. C.; ALMEIDA, F. T.; PAULINO, J. Classificação climática e balanço hídrico climatológico no estado de Mato Grosso. Nativa, v. 1, n. 1, p. 3443, 2013. https://doi.org/10.14583/23187670.v01n01a07

THOMSEN, I. K.; ELSGAARD, L.; OLESEN, J. E.; CHRISTENSEN, B. T. Nitrogen release from differently aged Raphanus sativus L. nitrate catch crops during mineralization at autumn temperatures. Soil Use Manage, v. 32, n. 2, p. 183-191, 2016.

https://doi.org/10.1111/sum.12264

TOPSEED - Tradição em Sementes. Crimson gigante. Santo Antônio da Posse: AGRISTAR, 2019. Disponível em: https://agristar.com.br/topseed/rabanete/crimso n-gigante/148/imprime. Acesso em: 31 dez. 2019.

VICIEDO, D. O.; PRADO, R. M.; TOLEDO, R. L.; SANTOS, L. C. N.; CALZADA, K. P. Response of radish seedlings (Raphanus sativus $\mathrm{L}$.) to different concentrations of ammoniacal nitrogen in absence and presence of silicon. Agronomía Colombiana, v. 35, n. 2, p. 198-204, 2017. https://doi.org/10.15446/agron.colomb.v35n2.62 $\underline{772}$ 